\title{
Development of an intelligent remote relay protection system with adaptive algorithms for determining the response setpoints
}

\author{
Olga Akhmedova*, and Anatoly Soshinov
}

Kamyshinsky Technological Institute (branch) of the Federal State Budgetary Educational Institution of Higher Education "Volgograd State Technical University"

\begin{abstract}
The severe consequences of emergency situations force us to look for ways to increase the stability of the complex, through the development of new algorithms for determining the setpoints for triggering protection and determining the locations of damage on overhead power lines (OPL). In electrical networks, devices for determining fault locations on power lines of $10 \mathrm{kV}$ and higher, based on measuring the parameters of the emergency mode, are widely used. When determining the location of the damage, not only the current and voltage parameters at the time of the accident are analyzed, but also the parameters of the overhead power line. OPL is characterized by the following main parameters: the specific active resistance $R$, the specific reactive resistance $X$, the specific active conductivity $G$ and the specific reactive conductivity B. As a rule, these parameters are attributed to the unit of the length of the overhead line (OL) and take linear values in the calculations. When analyzing power transmission lines, tabular approximate values of the longitudinal and transverse parameters in the substitution schemes are used, although solving problems in an unsophisticated form leads to significant refinements of the known solutions, since the overhead lines are affected by external atmospheric factors (changes in ambient temperature, soil humidity, wind forces, ice formation, etc.). In this paper we analyze the characteristics of these variables and evaluate the impact of the above factors on the linear longitudinal and transverse AL parameters obtained functional dependence of the influence of external factors on the setpoint triggering distance protection, developed a methodology to automatically adjust a setpoint of the complex intellectual and adaptive protection algorithm for relay protection, taking into account changes in climatic factors to reduce the length of the "dead zone" and increase the sensitivity of the protection. Also, the use of empirical data on the line parameters obtained from sensors in the calculations will allow us to more accurately determine the location of damage based on the use of remote methods.
\end{abstract}

\section{Introduction}

Problems associated with relay protection devices are one of the main causes of severe accidents that periodically occur in power systems around the world. According to the North American Electric Reliability Council, in $74 \%$ of cases, the cause of severe accidents in power systems was incorrect actions of the relay protection during the development of the accident, therefore, the reliability of the entire power system largely depends on the reliability of the relay protection [1].

Modern digital RPA devices have integrated the functions of relay protection, automation, measurement, regulation and control of the electrical installation within a single information complex. Such devices in the structure of the automated process control system (APCS) of an energy facility are terminal devices for collecting information.

The introduction of the IEC 61850 standard has led to the fact that relay protection and automation devices (RPA) are becoming available to an increasing amount of information, not only from measuring devices and sensors located in the same place, but also from other RPA devices. Devices based on a microprocessor element base, with memory and intelligence, are prepared for the implementation of new, more complex, but also more effective algorithms for relay protection and damage location. Thus, the task of developing relay protection algorithms that can work with an expanding information base is becoming increasingly urgent.

On this task, a number of foreign and domestic scientists, such as J. L. Artsishevsky, V. G. Berdov, V. A. Bogdan, D. S. Vasiliev, J. S. Gelfand, and M. L. Golubev, N. And. Dhoni, Yu. I. Zharkov, A. S. Zasypkin, M. Y. Kletzel, A. N. Kozhin, V. N. Kozlov, S. L. Kuzhekov, J. C. Kuznik, A. Kulikov, Yu. Ya. Lyamets, I. F. Marouda, V. I. nagay, V. I., Nagai, K. Nikitin, G. S. Nudelman, A. O. Pavlov, S. Ya. Petrov, V. A. Rubinchik, M. M. Means, A. M. Fedoseev, E. P. Figurnov, M. I. Tsarev, M. A. Shabad, etc.

The parameters of overhead power lines are used by the algorithms of many relay protection and automation devices (RPAD), their correct determination is necessary

Corresponding author: Ahmedova-olga@mail.ru 
to ensure the correct functioning of relay protection and automation systems. When determining the longitudinal and transverse parameters of the OPL, averaged data are used, such as the conductivity of the ground, the physical properties of the conductors, atmospheric conditions and the geometric location of the phase conductors relative to the surface of the earth and each other, which are assumed to be unchanged. RPADs may not function correctly (they may work incorrectly or unnecessarily, or they may not correctly determine the distance to the damage site) if their setpoints do not reflect the actual state of the controlled overhead line. It is important to clarify the parameters of overhead power lines for the correct determination of the relay protection settings using simulation models. This is confirmed by clause 5.11 of the standard of PJSC FGC UES - "emergency automation must ensure the effectiveness of the action and the use of minimal control actions".

The above factors make it necessary to develop an algorithm for the operation of the overhead line relay protection and determining the location of damage, taking into account changes in external environmental parameters and automatically adapting the setpoint.

The purpose of the work. Development of an intelligent complex for remote protection of overhead power lines with automatic correction of the influence of external factors on the setpoint.

\section{Analysis of the influence of external factors on the calculation error}

The principle of operation of distance protection is based on monitoring changes in the resistance. For example, if the protected object is a line, then in normal mode, the parameters of the bus voltage and current in the line are close to the nominal values:

$$
U_{ת}=U_{\text {норм }}, I_{\Omega}=I_{\text {норм }} \text {, proportion } z_{н}=\frac{U_{\text {норм }}}{I_{\text {норм }}}
$$

When a short circuit occurs, the bus voltage decreases, the line current increases, and the controlled resistance decreases

$$
z_{k}=\frac{U_{k}}{I_{k}}<z_{H}
$$

In turn, $z_{k}=z_{1} L_{l}$,

where $z_{\text {л }}$ is the resistance of $1 \mathrm{~km}$ of the line; $L_{l}$ is line length, $\mathrm{km}$.

Therefore, by monitoring the change in resistance, it is possible to determine the occurrence of a short circuit (SC) and to estimate the distance of the short circuit point.

One of the typical options for performing three-stage remote protection is shown in Figure 1.

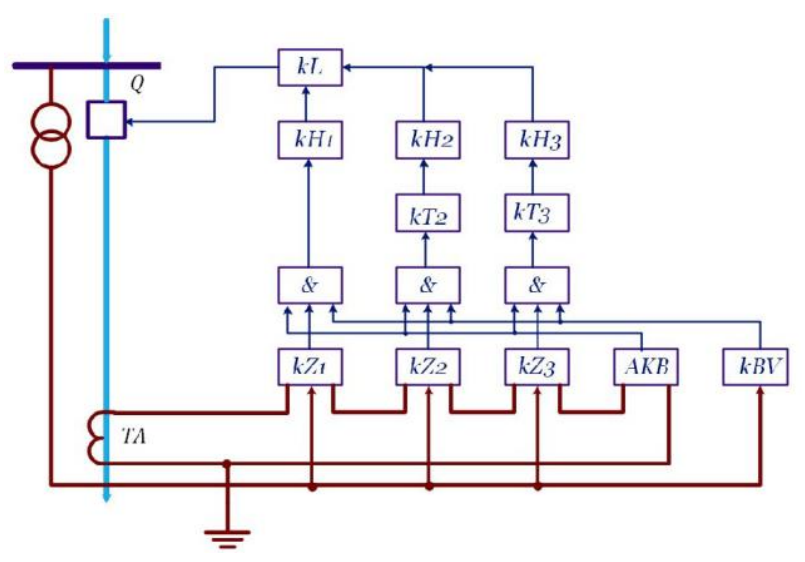

Fig. 1. Block diagram of remote protection.

Q-switch; TA-current transformer; kZ1, kZ2, kZ3resistance relay; AKB-swing blocking body; KBVvoltage circuit breaking blocking body; \& - logical multiplication body; kT1, kT2-time relay; kN1, kN2, $\mathrm{kN} 3$-indicator relays, $\mathrm{kL}$-intermediate relay.

For single-phase short circuits, the resistance at the input of the resistance measuring device is greater than for multi-phase short circuits at the same point, so the resistance measuring device cannot operate unnecessarily [2]. But the question is, will it work protection in this type of injury properly, if the set point depends on the resistance, i.e., under certain conditions, is proportional to the distance from the place of installation protection to place a short-circuit, provided that the changing external environment is neglected?

Variable factors that affect the accuracy of calculations for determining the location of damage are the active and reactive resistances of overhead lines, since these parameters are affected by external climatic factors that are not taken into account in the calculations.

Line resistance $z l$, calculated by the formula

$$
\underline{z}_{\pi}=\left(\underline{r}_{0}+j \underline{x}_{0}\right) L_{\pi}
$$

where $x 0$ is the linear inductive resistance of the direct sequence, $\Omega$

$/ \mathrm{km} ; r 0$ is the linear active resistance of the direct sequence, $\Omega$

$/ \mathrm{km} ; L \mathrm{l}$ is the line length, $\mathrm{km}$.

An overhead power line represents a circuit with distributed parameters. The assumptions about the concentration of really distributed parameters are valid for overhead lines whose length does not exceed $300-$ $350 \mathrm{~km}$.

We analyze the influence of the final conductivity of the earth and changes in environmental parameters on the longitudinal elements-resistances and transverse elements-conductivities of the U-shaped substitution circuit (Fig. 2). In the substitution scheme, we distinguish the longitudinal elements of the resistance of the power line: $\mathrm{Z}=\mathrm{r}+\mathrm{jxL}$ and the transverse elements of the conductivity: $\underline{Y}=\mathrm{g}+\mathrm{j} \underline{\mathrm{b}}_{\mathrm{C}}$. 


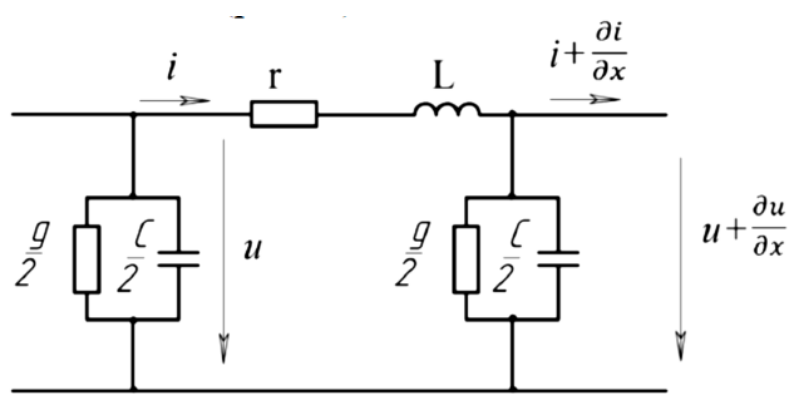

Fig. 2. U-shaped overhead power line replacement circuit.

As a rule, the linear parameters of the power line are considered to be constant values, the value of which is normalized in the reference literature. The given parameter data are calculated for normal external factors (ambient temperature $20^{\circ} \mathrm{C}$, sunny, ground resistance under the overhead line is constant, etc.), although in real conditions of operation of the overhead line, the climatic conditions change significantly not only during the calendar year, but also due to different climatic zones on the territory of the Russian Federation.

Let's analyze the influence of changes in atmospheric conditions on the linear parameters of an overhead power line.

The data given in the reference literature are calculated for a wire temperature of $20^{\circ} \mathrm{C}$ and do not take into account seasonal changes in ambient temperature, which are inherent in almost most of the Russian Federation.

The dependence of the active resistance on the temperature of the wire is determined by the formula [15]:

$$
R_{0 t}=R_{020}\left(1+\alpha\left(t_{n p}-20^{\circ}\right)\right)
$$

where $\mathrm{R}_{020}$ is the table value of the resistivity at a wire temperature of $20^{\circ} \mathrm{C} ; \mathrm{t}_{\mathrm{pr}}$ is the wire temperature, ${ }^{\circ} \mathrm{C} ; \alpha$ is the temperature coefficient of the electrical resistance, $\Omega / \mathrm{deg}$.

The temperature of the overhead power line wires depends on the cooling conditions in the environment (air temperature) and the current flowing through them. At maximum current loads under heating conditions, the wire temperature can reach $+70^{\circ} \mathrm{C}$, and at low ambient temperature and low loads up to $-50^{\circ} \mathrm{C}$, therefore, the resistivity can increase by $20 \%$ and decrease by $30 \%$.

From the equilibrium condition, the steady-state temperature of the wire is determined for any mode of operation of the overhead line [15]:

$$
I^{2} R_{020}\left(1+\alpha\left(t_{n p}-20^{\circ}\right)\right)=\sigma F\left(t_{n p}-t_{\text {ок }}\right)
$$

where I is the current passing the wire, A; $\sigma$ - coefficient of heat transfer equal to the amount of heat in 1 second from $1 \mathrm{~cm} 2$ of the surface of the wire when the temperature difference between wire and environment $1^{\circ} \mathrm{C} \mathrm{W} / \mathrm{m} 2 \cdot{ }^{\circ} \mathrm{F}$ - the surface of the cooling of wire, $\mathrm{cm} 2 ; \mathrm{t}_{\mathrm{ok}}$ - environment temperature, ${ }^{\circ} \mathrm{C}$.

The heat transfer coefficient can be defined as [8]:

$$
\sigma=\sigma_{л}+\sigma_{\kappa}=2,8\left(100+0,6\left(T_{n p}-273\right)\right) \cdot 10^{-2}+8,95 \sqrt{\frac{p \cdot v}{d}}
$$

where $\sigma \mathrm{l}$ is the heat transfer coefficient, determined by the heat output by radiation, $\sigma \mathrm{k}$ is the heat transfer coefficient, determined by convection, $p$ is the air pressure, $\mathrm{Pa}$; Тпр is the temperature of the wire, $\mathrm{K}, \mathrm{y}$ is the air velocity near the wire, $\mathrm{m} / \mathrm{s} ; \mathrm{d}$ is the wire diameter, $\mathrm{m}$

It follows from the expressions that the temperature of the wire is affected only by the wind speed, the amount of current passing through the line and the ambient temperature.

Taking into account the expression (6), we find the temperature of the overhead line wire from equation (5):

$$
t_{n p}=\frac{I^{2} R_{020}+\sigma F t_{o \kappa}-20 \sigma F}{\sigma F-I^{2} R_{020} \alpha}+20
$$

According to the requirements of GOST 839-80 "Non-insulated wires for overhead power lines", the long-term permissible temperature of the wires during operation should not exceed $90{ }^{\circ} \mathrm{C}$, the flow of current through the wire leads to its heating. So it is possible to skip the wire current exceeds the maximum allowable (alarm maximum current) amounting to $30 \%$ of DOP for a small period of time, while ensuring its mechanical stability, with the aim of greater clarity, the experimental analysis of the factors influencing the temperature of the wire, the time delay overcurrent relay protection is increased to eliminate triggering further disabling of the test line. At low and medium currents from the permissible, passing through the air line and not large wind loads, significant changes in the temperature of the wire occur mainly due to fluctuations in the ambient temperature. If the current load is more than $30 \%$ of the permissible line current and the wind speed is not high, then the current passing through the conductor has a noticeable effect on its heating. With an increase in wind speed, heat removal is significantly improved even with a large value of the flowing current (Fig. 3) [13, 14].

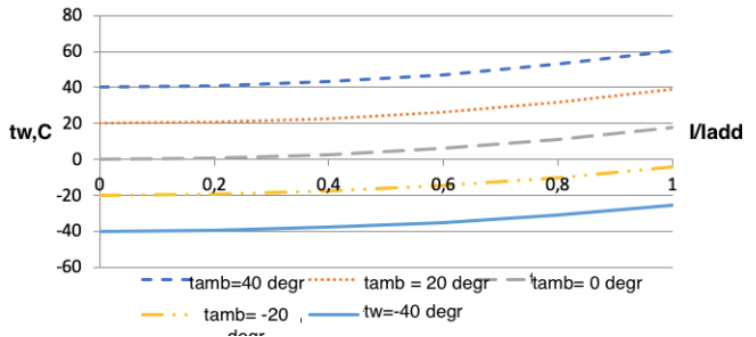

Fig. 3. Dependence of the temperature of the AC-120 overhead power line wire on the ambient temperature at the average wind speed $(v=2 \mathrm{~m} / \mathrm{s})$.

The analysis of the temperature conditions of the wires of various cross-sections used on overhead lines with a voltage of $110 \mathrm{kV}$ and above showed that the main dependences of the wire temperature on the flowing current, ambient temperature, wind speed are similar to those shown in Fig. 3. for the AC-120 wire. Consequently, the dependence of the resistance of the 
overhead power line wire at a changing ambient temperature for different brands of conductors will not differ from the graph shown in Fig. 4. I changed Fig. 4 and 5 in places, because it is more logical. The temperature dependence of wires of different crosssections is considered, and then the wire with the most common cross-section is analyzed.

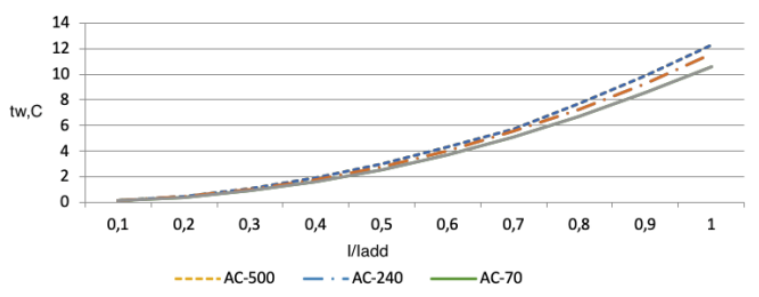

Fig. 4. Dependence of the temperature of the AC-500, AC-184, $\mathrm{AC}-70$ wires on the flowing current, ambient temperature tam $=0^{\circ} \mathrm{C}$, wind speed $4 \mathrm{~m} / \mathrm{s}$.

Based on the dependences shown in Fig. 3, 4, it follows that the temperature of the conductor does not fall below $-40^{\circ} \mathrm{CC}$ and does not rise above $70^{\circ} \mathrm{C}$, even at low wind speed and the current passing through the line is equal to the permissible current, therefore, we will analyze the dependence of the resistance of the overhead power line wire on the temperature in the specified range (Fig. 5). So for distribution networks, the most common voltage is $110 \mathrm{kV}$, then for the analysis of overhead lines, we will take a steel-aluminum wire of the AC brand with a cross-section of $120 \mathrm{~mm} 2$ with linear parameters $\mathrm{r} 0=0.249 \Omega / \mathrm{km}, \mathrm{x} 0=0.427 \Omega / \mathrm{km}, \mathrm{b} 0=2.66$ $\mathrm{Cm} / \mathrm{km}$.

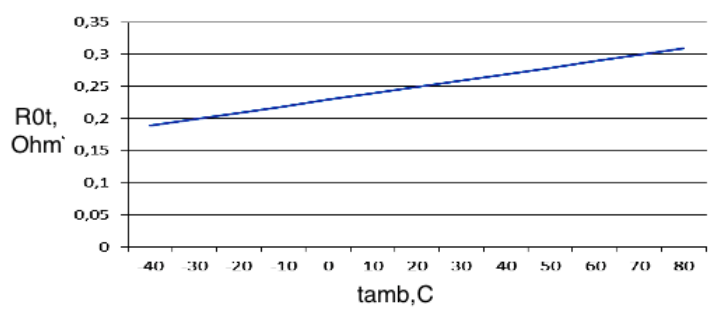

Fig. 5. Graph of the dependence of the resistance of the AC120 wire with a length of $1 \mathrm{~km}$ on the ambient temperature.

The graph shows that an increase in the temperature of the wire by $10^{\circ} \mathrm{C}$ leads to an increase in the resistance of the wire by $4 \%$.

The specific reactance depends on the flow coupling, which in turn depends on the relative position of the wires when taking into account the penetration of the earth's surface by the magnetic flux.

We determine the reactance of the overhead power line, taking into account the final conductivity of the soil.

If you imagine the earth as a conductor with large dimensions, through which alternating current flows, then due to the surface effect, it is not evenly distributed in the ground.

In an approximate analysis of the parameters of an overhead power line, the earth's conductivity is taken as an infinite quantity and, as a result of this assumption, it is assumed that all current is concentrated on the surface. In fact, the current penetrates to a certain depth, depending on the resistance of the soil and, taking into account that the soil is homogeneous, decreases as it moves away from the wire deeper and in both directions.

The method of analyzing the influence of the finite conductivity of the earth was proposed by Rüdenberg [12].

$$
\begin{aligned}
& \text { We get [12] } \\
& \qquad \underline{Z}_{3}=\frac{\underline{E}_{3}}{\underline{I}}=\left(\pi^{2} f+j 4 \pi f \ln \frac{0,178}{h \sqrt{f \gamma \cdot 10^{-9}}}\right) \cdot 10^{-9}= \\
& =\left(\pi^{2} f+29 f \lg \frac{0,178}{h \sqrt{f \gamma \cdot 10^{-9}}}\right) \cdot 10^{-4}
\end{aligned}
$$

We decompose the total resistance into the active and reactive components, then

$$
\begin{gathered}
R_{3}=\pi^{2} f \cdot 10^{-4} \\
X_{3}=29 f \lg \frac{0,178}{h \sqrt{f \gamma \cdot 10^{-9}}} \cdot 10^{-4}
\end{gathered}
$$

With an increase in the frequency and conductivity of the ground, the magnetic flux that closes in the ground will decrease, since the degree of inhomogeneity of the current distribution in the ground will increase, and if we take the ground as an infinitely conductive surface, then all the reverse current would be concentrated on the surface of the cylinder recess (earth) and there would be no need to consider the field that

To accurately determine the total wire resistance taking into account the conductivity of the earth must also consider the resistance of the wire and the clutch wire with part of the flow that closes in the air.

Define reactance generated by a part of a mud in the air flow, which in turn is created only by the current of the wire and coincides with it in phase, as for one wire single-phase two-wire line, provided that distance D between the wires is numerically equal to the height of the suspension $h$ of the considered wire [5].

$$
X_{в}=29 f \lg \frac{h}{r_{n p}} \cdot 10^{-4}
$$

And the inductance corresponding to the part of the flow closing in the air will be equal to:

$$
L_{в}=4,6 \lg \frac{h}{r_{n p}} \cdot 10^{-4}
$$

Considering the expressions (9), (10), (11) write down the total resistance of the wire

$$
\begin{aligned}
& \underline{Z}_{n p}=\underline{R}_{0 t}+\underline{R}_{3}+j \underline{X}_{3}+j \underline{X}_{s}= \\
& =\left[R_{020}\left(1+\alpha\left(t-20^{\circ}\right)\right)+\left(\pi^{2} f+j 29 f \lg \frac{0,178}{r_{0} \sqrt{f \gamma \cdot 10^{-9}}}\right) \cdot 10^{-4}\right]
\end{aligned}
$$


According to the expression (13), we divide the total resistance of the wire into active and reactive components:

$$
\begin{gathered}
\underline{Z}_{n p}=\underline{R}_{n p}+j \underline{X}_{L} \\
R_{n p}=\left(R_{020}\left(1+\alpha\left(t-20^{\circ}\right)\right)+\pi^{2} f \cdot 10^{-4}\right) \\
X_{L}=29 f \lg \frac{0,178}{r_{n p} \sqrt{f \gamma \cdot 10^{-9}}} \cdot 10^{-4}
\end{gathered}
$$

With an increase in the frequency and conductivity of the ground, the magnetic flux that closes in the ground will decrease, as the degree of inhomogeneity of the current distribution in the ground will increase. The reactance is created by a part of the flow closing in the air, which in turn is created only by the current of the wire and coincides with it in phase

To accurately determine the total wire resistance taking into account the conductivity of the earth it is also necessary to consider the resistance of the wire and the clutch wire with part of the flow that closes in the air.

From the expression (16) it follows that the reactance does not depend on the height of the suspension wire, as (10) increasing the height of the suspension reduces the dependence of XS from the stream, closing in the ground, but this increases the $\mathrm{XB}$ because of the increased flow, of a mud in the air.

The reactance of wire HPR is usually determined by the method of mirror images, i.e. the system of "wire - a dummy wire, passing under the ground" with the distance between the wires $d$ said, what would the resistance wire to two-wire line was equal to the resistance wire in the "wire-ground".

$$
D_{3}=\frac{0,178}{\sqrt{f \gamma \cdot 10^{-9}}} \mathrm{cM}
$$

where $\mathrm{f}$ is the frequency, $\mathrm{Hz} ; \gamma$ is the ground conductivity, See

The reactance of the conductor of the "wire-ground" system»

$$
X_{n p}=29 f \lg \frac{D_{3}}{r_{0}} \cdot 10^{-4} O_{M} / \kappa M
$$

where $\mathrm{r} 0$ is the radius of the wire, $\mathrm{m}$.

From expressions (17), (18), it follows that the value of the reactance of the wire depends on the resistance of the ground, which varies over a wide range under the influence of factors such as temperature, humidity.

From expressions (16), (17), it follows that the value of the reactance of the wire depends on the resistance of the ground, which varies over a wide range under the influence of factors such as temperature, humidity [11].

For a more precise estimate of the earth's resistance, we will consider it two-layer: the first layer is $2.5 \mathrm{~m}$ deep, and the depth of the second layer is determined, based on the method of mirror images, as half of the double height of the suspension of the overhead power line wire above the earth's surface. Then we get the equivalent resistance

$$
\rho_{\text {эк }}=\frac{h}{\sum_{\kappa=1}^{3} \frac{\Delta d_{\kappa}}{\rho_{\kappa}}+\frac{\Delta d_{2}}{\rho_{2}}}
$$

where $\mathrm{h}$ is the height from the dummy wire located in the ground to the ground surface, $\mathrm{m} ; \Delta \mathrm{dk}$ - the maximum depth of soil wetting, $\mathrm{m} ; \Delta \mathrm{d} 2$ - the thickness of the soil not subject to seasonal changes in humidity, $\mathrm{m} ; \mathrm{pk}$ - the resistance of the soil on the site $\Delta \mathrm{dk}, \Omega / \mathrm{m}$; $\mathrm{p} 2$ - the resistance of the soil on the site $\Delta \mathrm{d} 2, \Omega / \mathrm{m}$.

$$
\Delta d_{2}=h-\sum_{\kappa=1}^{3} \Delta d_{\kappa}
$$

Figure 6 shows the dependence of the reactance of the wire at different ground resistances on seasonal fluctuations in humidity and temperature by month.

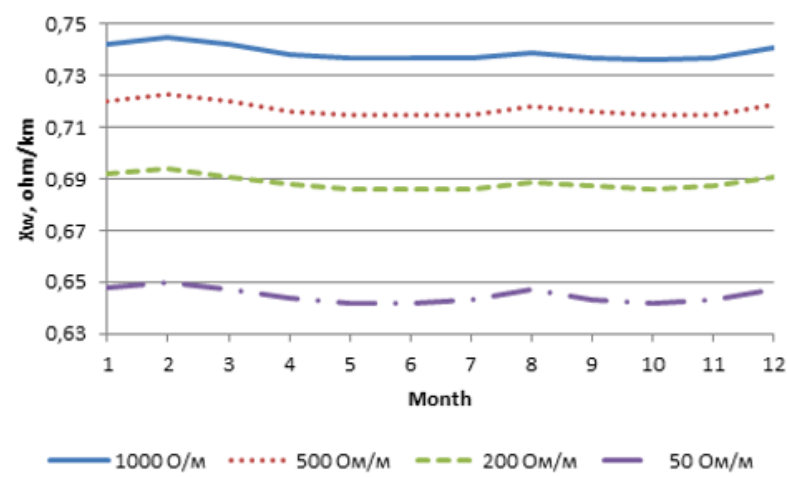

Fig. 6. The dependence of the reactance of the wire at different ground resistances on seasonal fluctuations in humidity and temperature by month.

When projecting the dependencies graphically presented in Fig. 6, there is a coincidence of the trends of the curves from the change in months, therefore, regardless of the structure of the soil, a clear seasonal dependence remains, which must be taken into account when calculating the resistance of the wire, we denote it by $\chi$.

Figure 7 shows the resistance of the wire, taking into account the final conductivity of the earth, but without the seasonal coefficient, the error was 7-8\%. 


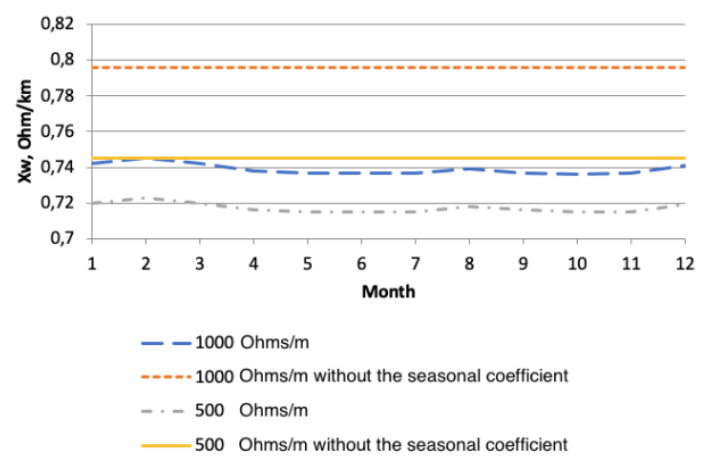

Fig. 7. The dependence of the reactance of the wire at ground resistances of $1000 \Omega / \mathrm{m}$ and $500 \Omega / \mathrm{m}$ without taking into account the seasonal coefficient and taking it into account.

When calculating reactance by the method of mirror images, the ground effect is neglected since it is assumed that the soil is considered infinitely conducting surface (a mirror), therefore, the magnetic field lines are closed only in the air, and the reverse current concentrate on the surface of the earth, and the distance between the dummy wire and the wire of overhead transmission lines is taken equal to twice the height $2 \mathrm{~h}$ of the suspension (Fig. 8).

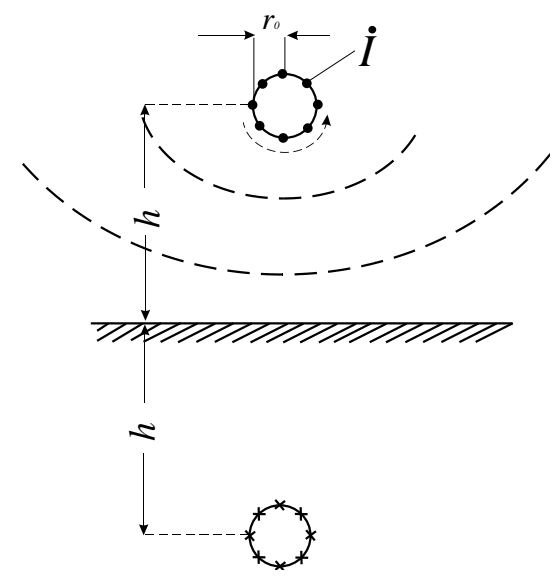

Fig. 8. The system "line wire- fake wire" without taking into account the conductivity of the earth.

In fact, the earth has a finite conductivity, therefore, when applying the method of mirror images, this must be taken into account, by placing the "mirror" at a distance of $0.5 \mathrm{Dz}$ from the axis of the wire (Fig. 9).

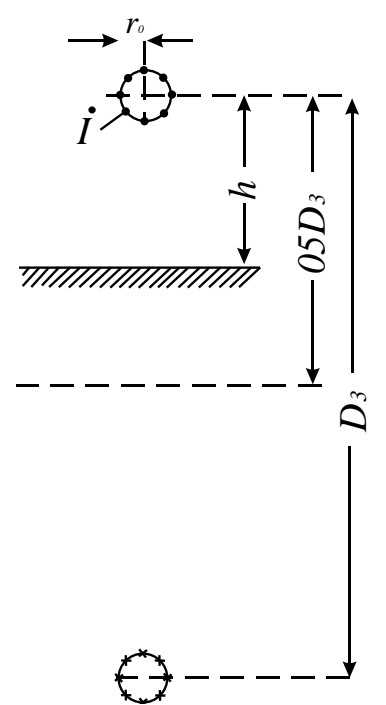

Fig. 9. The system "line wire-fake wire" taking into account the final conductivity of the earth.

The increase of the distance d said (the amount of the order of $1 \mathrm{~km}$ ) compared to D (the value of the order of $10 \mathrm{~m}$ ) does not entail a proportional increase of reactive resistance, as the distance from the axis of the wire length of power lines is increasing and the value of $\mathrm{N}$ decreases, so the upslope flow, mating with the wire much, behind rise the distance between the axes of the wires.

Let's compare $\mathrm{X}$ at the distance between the wires $\mathrm{D}$ $=5 \mathrm{~m}$ with Xpr at $\mathrm{Dz}=935 \mathrm{~m}$, the radius of the wire in both cases gpr $=0.00429 \mathrm{~m}$, the brand AC-120.

$$
X=0,145 \lg \frac{5}{0,00429}=0,47 O_{M} / \kappa M
$$

Reactivity of the wire of the "wire - to-ground" loop from (33)

$$
X_{n p}=0,145 \lg \frac{935}{0,00429}=0,773 O M / \kappa M
$$

The ratio of the resistances

$$
\frac{X_{n p}}{X}=\frac{0,773}{0,47}=1,65
$$

When

$$
\frac{D_{3}}{D}=\frac{935}{5}=187
$$




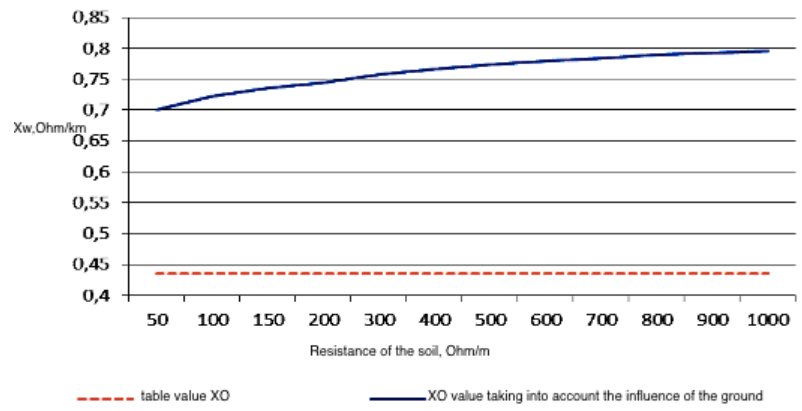

Fig. 10. Dependence of the change in the total linear resistance of the wire on the ambient temperature, taking into account the final conductivity of the soil.

It follows from Fig. 10 that with respect to the constant value of the total line resistance, which is taken into account in the calculations, the influence of the ambient air temperature significantly changes it, if we estimate the error at the two extreme points (at a temperature of $40^{\circ} \mathrm{C}$ and $-40^{\circ} \mathrm{C}$ ), the error will be $8 \%$ and $23 \%$, respectively. When taking into account the final conductivity for the same ambient temperatures, the error will be $48 \%$ and $19 \%$.

\section{Development of algorithms for remote protection and detection of damage sites with adaptive setpoint}

According to the above conditions, we will calculate the short-circuit current for the overhead power transmission line of the electric network (Fig. 11). This overhead line is a main line with branch and pass-through substations, made of AC - 150 single-chain wire, the total length is $93.62 \mathrm{~km}$.

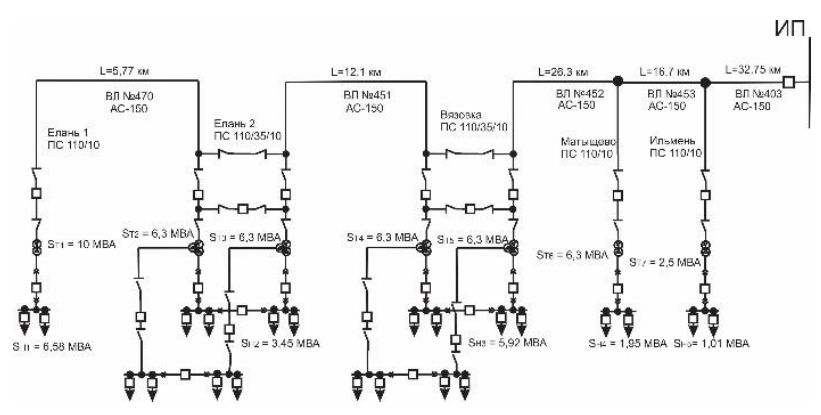

Fig. 11. Main power transmission line.

The analysis of the influence of external factors on the short-circuit current is presented in Fig. 15, the value of short-circuit currents for different types of damage was determined at the value of the ground resistance of $20 \Omega / \mathrm{m}$.

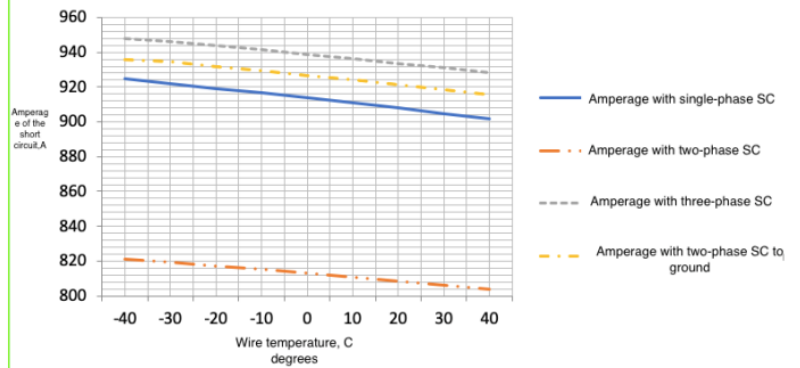

Fig. 12. Dependence of the change in the short-circuit current for various types of damage on the temperature of the overhead line wire.

The probability of short circuits in $110 \mathrm{kV}$ electrical networks for various types of damage is distributed as follows: three-phase short circuits account for $4 \%$ of damage, two - phase ground faults $-8 \%$, two-phase faults- $5 \%$, single-phase faults- $83 \%$. Determining the relay protection setpoint current from the maximum current of a three-phase short circuit may lead to incorrect actions of the relay protection devices. Therefore, when carrying out a calculation using three phase current short-circuit percentage error in the determination of the setpoint current will resemble the following: when two-phase short circuit will be $22 \%$, single-phase $-9 \%$, with two-phase to earth $-7 \%$, calculations were made with the soil resistance is $20 \Omega /$ m (Fig. 12).

Changes in the ground resistance affect only those types of damage at which a zero-sequence current appears, so single-phase short and two-phase shortcircuit to the ground are taken into consideration. Taking into account two factors of influence (fluctuations in the temperature of the wire and the resistance of the ground) leads to a calculation error in determining the response current at a single-phase short circuit up to $17 \%$, and at a two-phase ground fault- $7 \%$.

The dynamics of the change in the resistance of the protection setpoint with a single-phase short circuit and a change in the ground resistance is shown in Fig. 14. Analyzing the data obtained, it can be seen that the change in resistance ranges from 14\% (ground resistance of $20 \Omega / \mathrm{m}$ ) to $28 \%$ (ground resistance of $1000 \Omega / \mathrm{m}$ ) relative to the resistance calculated for symmetrical damage, therefore, remote protection, which is minimal, may not work with asymmetric short circuits, provided that the soil dries and its resistance increases. 


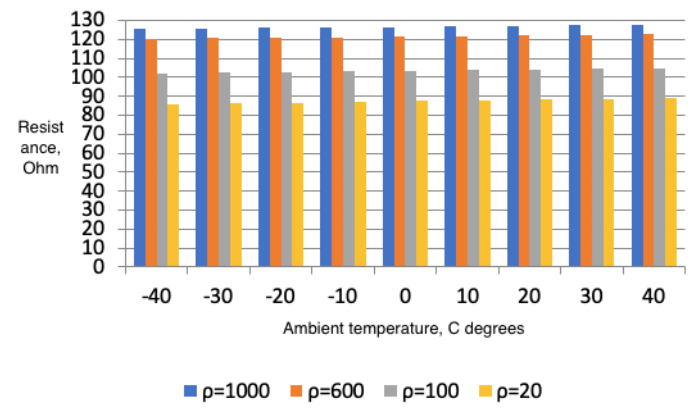

Fig. 13. Changes in the resistance of the protection setpoint at a single-phase short circuit and changes in the ground resistance of the overhead line.

The change in the resistance of the protection setpoint at a three-phase short circuit due to seasonal temperature fluctuations is insignificant and can be completely ignored (Fig. 13). Since the zero sequence does not participate in the calculations of this type of damage, the remote protection setpoint does not change even at different ground resistances, so the calculation according to the traditional method gives such a significant error indicator.

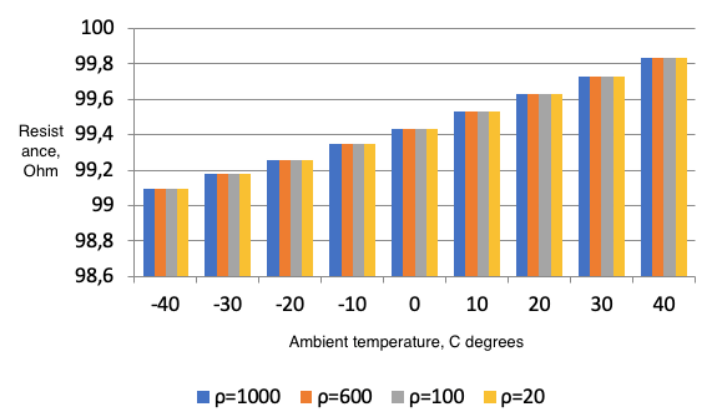

Fig. 14. Changes in the resistance of the protection setpoint for three-phase short circuit and changes in the ground resistance of the overhead line.

Since the resistance measuring body that has a larger response setpoint is more sensitive, it is more appropriate to use as a setpoint not tabular data, but directly obtained from external parameter sensors to reduce the length of the "dead zone". Accordingly, VL is made by cable grade AC-150 length 93,62 km full grid resistance will be of $43.47 \Omega$, while taking into account the resistance of the soil and the ambient temperature will range from $99 \Omega$ to $99.8 \Omega$, hence, the length of the "zone of failure" will decrease in 2 times.

Figure 14 shows the change in the current of a threephase and two-phase short circuit from the length of the overhead power line, as well as a straight line indicates the value of the current protection tripping current, which is a constant value. The dead zone for a threephase short circuit will be $31 \%$, for a two-phase short circuit- $48.3 \%$.

Consider the changes in the length of the "dead zone" for different types of short-circuit currents and the resistance of the ground under the overhead line (Fig. 15 and 16).

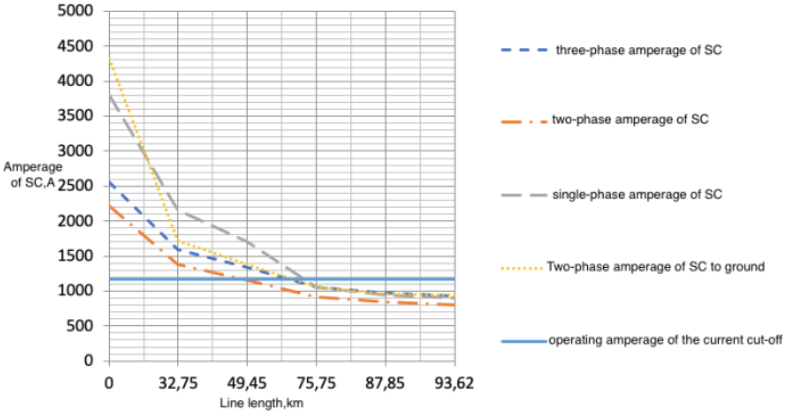

Fig. 15. Change in the value of the "dead zone" at the ground resistance of $20 \Omega / \mathrm{m}$, the setpoint is calculated according to the traditional method of overhead transmission.

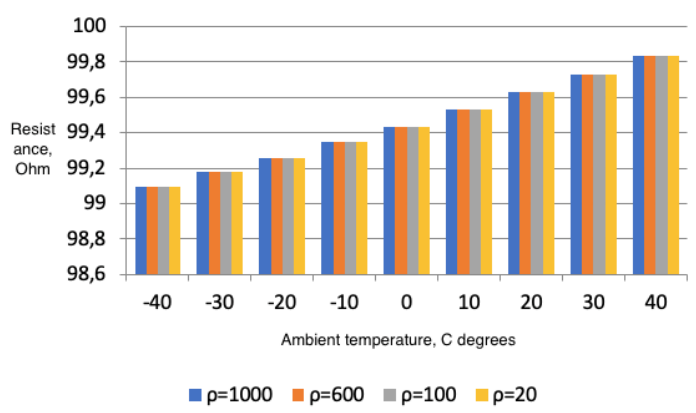

Fig. 16. The change in the value of the "dead zone" at the ground resistance of $1000 \Omega / \mathrm{m}$, the setpoint is calculated according to the traditional method of overhead transmission «.

The analysis of the dependences presented in Figs. 17 and 18 shows that, depending on the resistance of the ground under the overhead power line, the zone of "nonoperation" of the relay protection changes. The "dead zone" for a three-phase short circuit with a ground resistance of $20 \Omega / \mathrm{m}$ will be $33.1 \%$, and with a resistance of $1000 \Omega / \mathrm{m}-12.6 \%$, the remaining data are summarized in Table 1

Table 1. The value of the" dead zone " for various ground resistances.

\begin{tabular}{|c|c|c|c|}
\hline \multirow[t]{2}{*}{ № } & \multirow[t]{2}{*}{$\begin{array}{l}\text { Type of } \\
\text { damage }\end{array}$} & \multicolumn{2}{|c|}{$\begin{array}{c}\text { Length of the } \\
\text { «dead zone», } \%\end{array}$} \\
\hline & & $\begin{array}{c}\rho=20 \Omega / \mathrm{m} \\
t_{\mathrm{pr}}=40^{\circ} \mathrm{C}\end{array}$ & $\begin{array}{c}\rho=1000 \Omega / \mathrm{m} \\
t_{p r}=-40{ }^{\circ} \mathrm{C}\end{array}$ \\
\hline 1 & $\begin{array}{l}\text { Three-phase short } \\
\text { circuit }\end{array}$ & 33.1 & 26.11 \\
\hline 2 & $\begin{array}{l}\text { Two-phase short } \\
\text { circuit }\end{array}$ & 47.18 & 40.15 \\
\hline 3 & $\begin{array}{l}\text { Single-phase short } \\
\text { circuit }\end{array}$ & 26.11 & 19.08 \\
\hline 4 & $\begin{array}{l}\text { Two phase short } \\
\text { circuit to ground }\end{array}$ & 33.1 & 30.4 \\
\hline
\end{tabular}

Ignoring the seasonal change in ground resistance or its change over the course of the power line when calculating relay protection settings can lead to significant errors

The head subsystem consists of a receiving modem and a dispatcher computer with installed software. The head subsystem consists of a remote relay protection system with adaptive algorithms for determining the setpoints of an overhead power line. The peripheral 
subsystem consists of measurement and transmission stations.

Posts measurement will be installed in the long air lines, seat selection is based on the topography of the passage of lines, in areas most susceptible to icing and heterogeneous terrain of the soil are based on many years of experience of operating overhead.

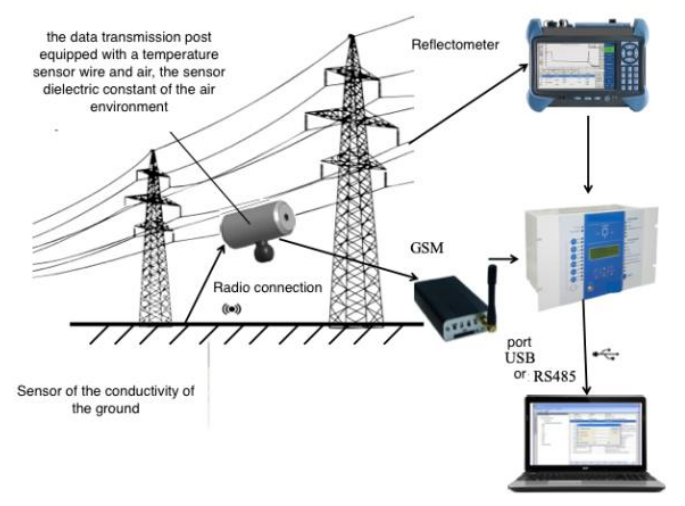

Fig. 17. Concept of an intelligent remote relay protection system with adaptive algorithms for determining the setpoints of an overhead power line.

The measurement station consists of three galvanically unrelated parts with separate power supply: one of them (the wire temperature measurement module) is attached to the wire, the second is located on the support body, and the third is located in the ground near the support, directly under the overhead power line.

The implementation is supposed to be carried out on the manufactured elements and blocks, which will speed up the process of implementing the relay protection system in the electrical networks.

The first part of the system is implemented on the blocks of the automated ice detection system on the ASTROSE overhead line, manufactured by Sovtest ATA LLC, Kursk. This system monitors the ice, snow and wind loads of power lines, as well as controls the permissible current load of the wire.

The modules are installed on wires mainly near the traverse of the supports within one span and are located at a distance of $500 \mathrm{~m}$ from each other.

To control humidity and ambient temperature, a microprocessor sensor DVT-02M, manufactured by GC Teplopribor, is used. It is intended for use where aggressive substances may be present in the air, as well as short-term condensation of moisture is possible.

Humidity sensors are equipped with a new humidity sensor with better time stability, with the departure of parameters-no more than $\pm 1.2 \%$ relative humidity per year at $50 \%$ relative humidity; short-term operation of the humidity sensor at a temperature of $+100^{\circ} \mathrm{C}$ is allowed;

The third part is the PASCO wireless digital conductivity sensor, manufactured by Zeltix, Yekaterinburg.

To determine the location of the damage, a reflectometer for power lines TDR-109 STRIZH-S, manufactured by OOO "Electronpribor", is used.

TDR-109 STRIZH-S is a high-precision 3-channel digital reflectometer, specially designed to determine the distances to any types of inhomogeneities and damages in power cable lines: breakage, short circuit, coupling, cable splice, parallel branch, cable short circuit.

The detection of ice on the overhead line is also carried out with the help of a reflectometer. The pulse signal during the location sensing of the power line in the presence of icy deposits on it undergoes certain changes. This is due to the change in the permittivity of the space between the wires of the line when ice appears. This increases the capacitance between the line wires. An increase in $\mathrm{C}$ leads to a decrease in the wave resistance of the line. An increase in $\mathrm{C}$ also causes a decrease in the speed of propagation of the signal along the line. In this case, there is an additional delay of the pulse in time due to a decrease in the speed of propagation of the signal and a decrease in the amplitude (attenuation) due to an increase in losses in the dielectric (ice deposits) due to its heating. Consequently, when ice appears, the pulses reflected from the above-mentioned line inhomogeneities, which can be considered reference points, will undergo an additional delay in arrival time and an additional decrease in amplitude. It is proposed to use the combined manifestation of these factors as a

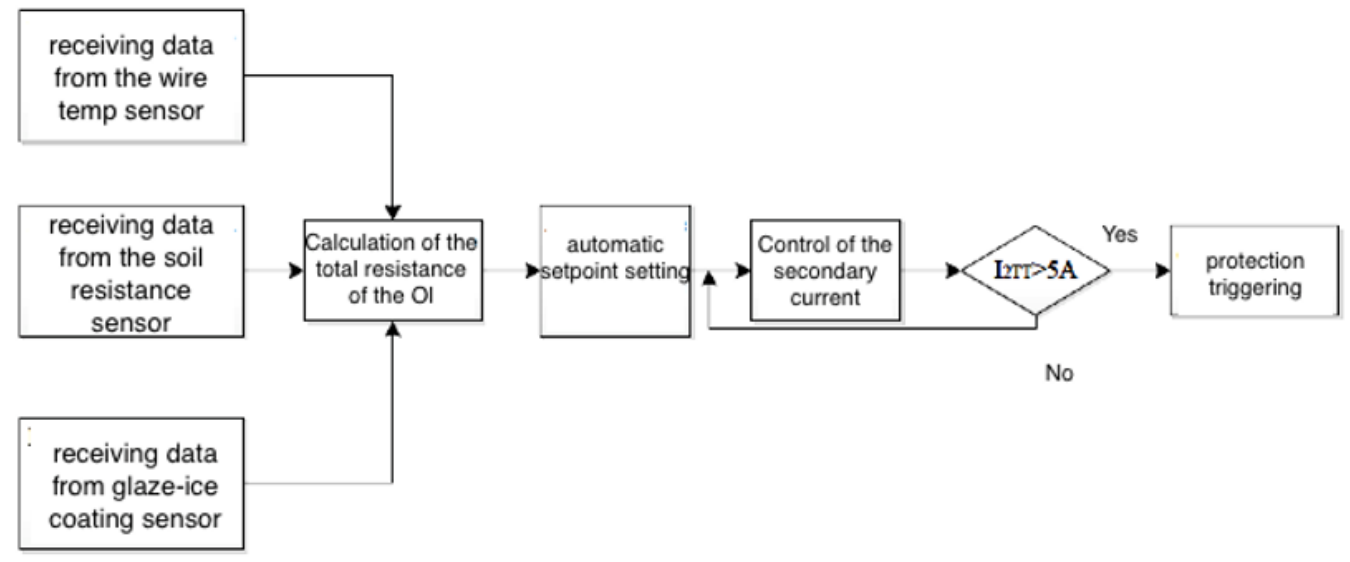

Fig. 18. The algorithm of functioning of the distance protection with adaptive setpoint. 


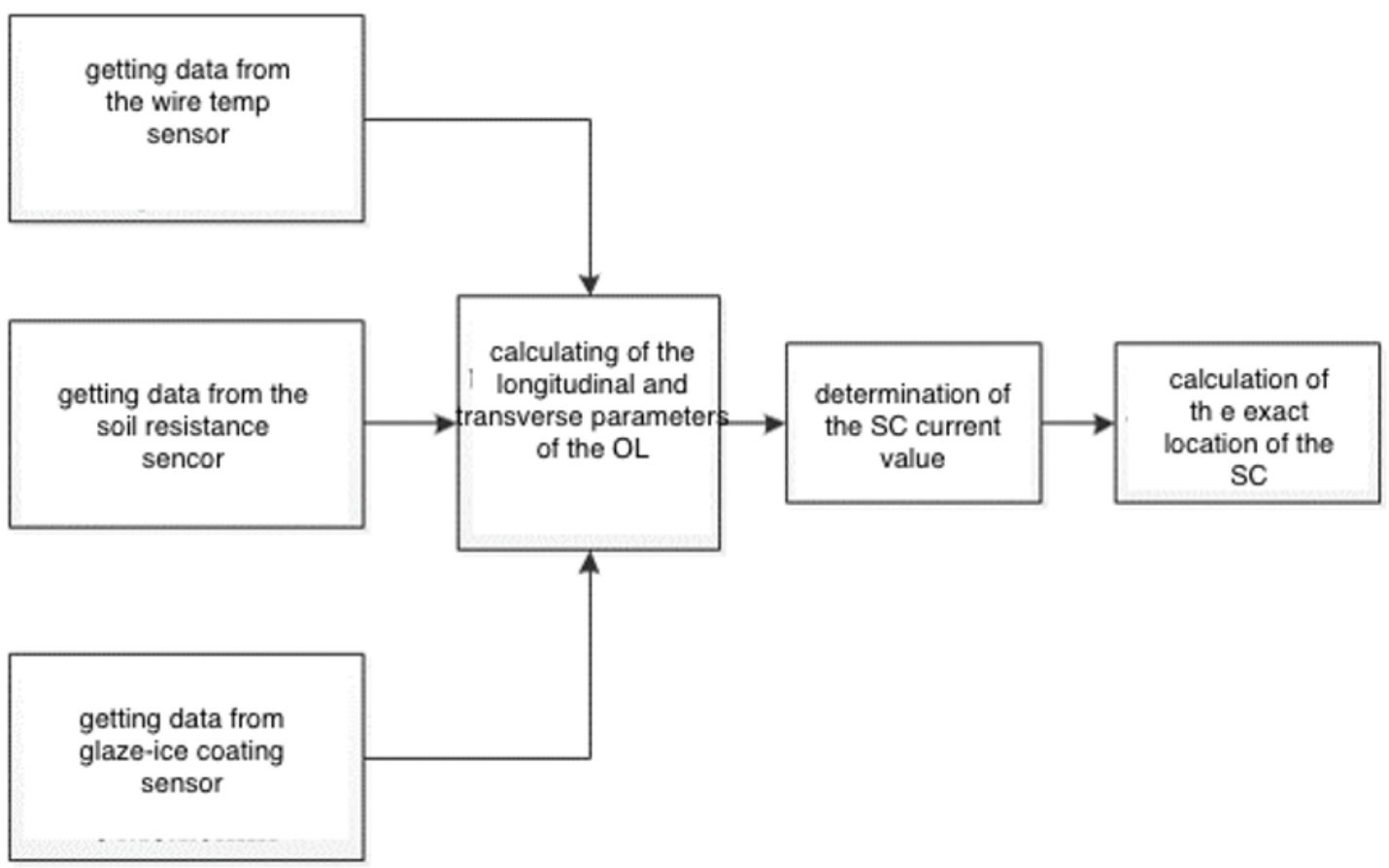

Fig. 19. Algorithm for the refined determination of the fault location on the overhead line.

criterion (indicator) of the appearance of ice on power lines.

Figure 19 shows the developed algorithm for the operation of remote protection, which allows you to take into account changes in external factors and adapt the trigger setpoint.

Calculation procedure according to the proposed algorithm for determining the remote protection settings:

1. Determine the parameters of the power transformers of the forward, reverse and zero sequences.

2. Sensors are installed on the protected overhead line that record data on the ambient temperature, air humidity, wind speed and ground humidity under the overhead power line, the measurement parameters are transmitted via communication channels to the relay protection system for further analysis.

3. Based on the data obtained, the actual longitudinal and transverse parameters of the overhead power line of the direct, reverse and zero sequences are calculated.

4. Based on the data on the overhead line of the network, the substitution circuits are converted and the equivalent active, reactive resistances and equivalent EMF are determined.

5. The total resistance of the overhead power line is calculated based on the data on external environmental factors and the resistance unit setpoints are automatically set.

6. In case of a short circuit on the protected line, we receive data on the operating mode of the line from current and voltage transformers.

7. The damage resistance $\mathrm{Zk}$ is compared with the protection setpoint $\mathrm{Zp}$, if $\mathrm{Zk} .<\mathrm{Zp}$, the protection is triggered.

When calculating the protection setpoint, taking into account the external environmental parameters, it becomes possible to reduce the value of the "dead zone" of the first stage of remote protection, by using the parameters of the overhead line that actually reflect the state of the line. The "dead zone" occurs at the end of the protected line, because due to the large extent of the damage resistance, $\mathrm{Zk}$ becomes less than the protection setpoint Zp.

Remote protection is used for a long time to protect networks of complex configuration and high voltage. The executive base of the resistance relay underwent changes from electromechanical to microprocessor, but the changes were more related to the hardware, rather than the algorithms of operation. The main disadvantage of current protection is the dependence of the zone of their action on the short-circuit current, which does not allow in some cases to have sufficient sensitivity of current protection, especially its high-speed stages. In addition, in complex closed networks (for example, in a ring network with two power sources), the selectivity of current protection cannot be ensured. The use of the setpoint adaptation algorithm in remote protections allows you to take into account the decrease in the value of the short-circuit current at the end of the protected line, automatically set the resistance response setpoint reflecting the real longitudinal and transverse parameters of the overhead line, thereby reducing the length of the" dead zone " and increasing the sensitivity of this type of protection.

To restore the normal operation of electric power systems, to reduce damage and costs, it is necessary to quickly and accurately determine the places of damage to power lines. All of the above requirements are met by remote methods of damage detection, provided that the accuracy of calculations is increased. As a rule, the calculation of the WMD setpoints is based on the values of short-circuit currents, which directly depend on the 
longitudinal and transverse parameters of the protected power line.

To calculate the damage location, data on external environmental parameters obtained from sensors installed on the overhead line are used, rather than tabular data that do not reflect the real picture of what is happening on the overhead line. As a result, the accuracy of determining the location of the short circuit on the overhead line is significantly increased.

Based on the developed algorithms, an intelligent complex of the relay protection system is proposed, which forms a control action on the basis of objective data obtained from sensors installed on the power line in real time. This system has an increased sensitivity coefficient of protection, which reduces the value of the "dead zone", thereby increasing the reliability of the installed protection. New algorithms for the operation of the RZ device have been developed to reduce the number of "false positives" and "failures". A program that implements the developed algorithms, which allows you to calculate the response parameters and determine the type and location of damage.

\section{Conclusion}

1. From the experience of operating relay protection systems, it follows that the setpoint level is influenced by climatic factors and seasons, and therefore, to increase the reliability of the operation of the relay protection system, it is necessary to introduce an automatic setpoint current correction unit into the system.

2 . To prove the dependence between longitudinal and transversal parameters of a transmission line and climatic factors of the environment: if the current load of more than $30 \%$ of the permissible rated current of the line and the wind speed is not large, the current flowing through a conductor, has a significant impact on its heating; at low and medium currents from a valid, passing through the overhead line and not the large wind loads the resistance change of the wire are due to the air temperature fluctuations;

3. The temperature increase leads by $10^{\circ} \mathrm{C}$ leads to an increase in the wire resistance by $4 \%$, the magnitude of error relative to DC resistance in the two extreme points is from $8 \%$ to $23 \%$, while accounting and finite conductivity of the soil ranges from 19 to $48 \%$.

4. The relay and the ISR must be installed on the VL sensor wire temperature, soil moisture, information at the time of the accident will be transmitted to the computing unit and to calculate the fault location given the correct data about the parameters of the lines.

5. An algorithm for intelligent remote relay protection has been developed, which takes into account changes in external factors and adaptive calculation of the response resistance, which will reduce the length of the "dead zone" and increase the sensitivity of the protection at the end of the line.

\section{References}

1. Gurevich, V. I. Microprocessor protection relays. Device, problems, prospects / V. I. Gurevich-M.: Infra-Engineering, $2011--336 \mathrm{p}$.

2. Akhmedova, O. O. Reliability of operation of relay protection in power engineering / O. O. Akhmedova, A. N. Shilin / / Innovative, information and communication technologies. INFO-2016: sat. tr. XIII International Scientific and Practical Conference (Sochi, October 1-10, 2016) / Editorial board: S. U. Uvaysov (main ed.), I. A. Ivanov (rel.) [and others] / Association of Graduates and employees of the VVIA named after prof. Zhukovsky [et al.]. - Moscow, 2016. - C. 175-176.

3. Zharkov, Yu. I. Intellectualization of microprocessor terminals of relay protection and automation of electric traction networks of alternating current / Yu. I. Zharkov, I. L. Shpanchenko / / Electrification and organization of high-speed heavy-weight corridors on railway transport: theses of reports of the IV International Conference. symposium Eltrans ' 2007, St. Petersburg, October 23-26, 2007-p. 41-42.

4. Multidimensional relay protection. Part 1. Theoretical prerequisites / Yu. Ya. Lyamets [et al.]. //Electricity. - 2009. - No. 10. - p. 17-25.

5. Margolin, N. F. Resistance of overhead transmission lines / N. F. Margolin-M.: Mosoblpoligraf, 1937. $61 \mathrm{~s}$.

6. Nagai, I. V. Analysis of the functioning of resistance measuring bodies with the control of emergency components / I. V. Nagai / / Izv. vuzov. Electromechanics. - 2008. - Special Issue. - p . 100-101.

7. Guidelines for the calculation of short-circuit currents and the choice of electrical equipment / ed. by B. N. Neklepaev. - M.: Publishing House of the National Center of ENAS, 2001. - 152 p.

8. Pospelov, G. E. Influence of wire temperature on electric power losses in active resistances of wires in overhead power transmission lines / G. E. Pospelov, V. V. Yershevich / / Electricity. 1973. No. 10. pp. 81-83.

9. Chernobrov, N. V. Relay protection of energy systems: textbook. manual for technical schools / N. V. Chernobrovov, V. A. Semenov-M.: Energoatomizdat, 1998. - 800 p.

10. Bass, E. I. Relay protection of electric power systems: Textbook / E. I. Bass, V. G. Doroguntsev. Edited by A. F. Dyakova - M.: Publishing house of MEI, 2002.- 296 p.

11. Dolin P. A. Osnovy tekhniki bezopasnosti v elektroinstanovkakh/ P. A. Dolin-M.: Energoatomizdat, 1984 - - 448 p.

12. Ollendorf. Erdstrome. Berlin 1928.

13. Pospelov, G. E. Influence of wire temperature on electric power losses in active resistances of wires in overhead power transmission lines / G. E. Pospelov, V. V. Yershevich / / Electricity. 1973. No. 10. pp. 81-83. 
14. Burgsdorf, V. V. Heating of wires of overhead power lines and existing norms / V. V. Burgsdorf / / Electricity. 1937. - No. 17-18. - p. 40-44.

15. Gerasimenko A. A. Transmission and distribution of electric energy: A textbook/ A. A. Gerasimenko, V. T. Fedin. - Rostov-n / d.: Feniks; Krasnoyarsk: Publishing projects, 2006. - 720 p. 